\title{
EL VALOR DEMOCRÁTICO DE LA SOCIEDAD CIVIL: UNA RESPUESTA A LA DESAFECCIÓN ${ }^{1}$
}

\author{
THE DEMOCRATIC VALUE OF CIVIL SOCIETY: \\ AN ANSWER TO DISAFFECTION
}

\author{
Domingo García Marzá ${ }^{2}$ \\ Universitat Jaume I (España)
}

Recibido: 30-11-2014

Aceptado: 02-02-2015

Resumen: La tesis que defiende este texto es que es posible enfrentarse a la desafección y recuperar la fuerza de la democracia si pensamos en una democracia de doble vía. Se define en primer lugar en qué consiste la desafección y cómo se ha producido. Posteriormente se introduce el concepto de sociedad civil a partir de la idea de una democracia de doble vía, donde la democracia se entiende desde la complementación entre el estado y la sociedad civil. Por último, se esbozará una propuesta de estructuración institucional de la sociedad civil, capaz de recuperar la fuerza inherente al mundo de la vida y dar cuenta de nuestras capacidades para actuar.

Palabras-clave: democracia, desafección, sociedad civil, participación.

\begin{abstract}
The argument put forward by this text is that it is possible to face disaffection and regain the strength of democracy if we think of a democracy of double track. It first defines what disaffection means and how it was produced. Then the author introduces the concept of civil society, set out by the idea of a two-way democracy, where democracy is understood from the complementation between the state and civil society. The article ends with a proposal for an institutional structuration of civil society, able to retrieve the strength inherent to the life-world and able to account for our ability to act.
\end{abstract}

Key-words: democracy, disaffection, civil society, participation.

[1] Este estudio se inserta en el Proyecto de Investigación de I+D+I "Política, Empresa y Educación desde la Neuroética Aplicada” FI2013-47136-C2-2-P, financiado por el Ministerio de Economía y Competitividad.

[2] (garmar@uji.es) Catedrático de Ética de la Universitat Jaume I de Castellón y Director del Departamento de Filosofía y Sociología. Ha ampliado estudios de Política en Francfurt (Alemania) y de Ética económica en ST.Gallen (Suiza), en la Universidad de Notre Dame (Estados Unidos) y en Magee College of the University of Ulster (Irlanda del Norte). Sus líneas de investigación incluyen: democracia deliberativa, ética empresarial, diseño institucional, sociedad civil y hermenéutica crítica. 
El objetivo de esta contribución es modesto y solo pretende ayudar a pensar alternativas viables a la situación actual de la democracia desde sus bases éticas, desde el saber moral implícito o presupuesto en nuestra forma de percibir y entender la democracia. Ayudarnos a reflexionar y discutir, sabiendo que aquello que entendamos por democracia acaba influyendo en la realidad llamada democracia. Como muy bien muestra la actual desafección.

La propuesta que deseo argumentar consiste en afirmar que debemos ampliar el concepto de democracia actualmente existente hasta conseguir incrustarlo de nuevo en los contextos del mundo de la vida, en concreto, en su plasmación institucional. Debemos dejar de confundir democracia y política, debemos recuperar la participación y frenar la colonización de la sociedad civil por parte de los políticos, devolverlos a su lugar, que no es otro que el sistema político. Mi tesis es la siguiente: es posible enfrentarse a la desafección y recuperar la fuerza de la democracia si pensamos en una democracia de doble vía, donde la sociedad civil pueda desarrollar todo el potencial contenido en la autonomía moral y en la participación que la misma exige. El esquema que les propongo es el siguiente:

En primer lugar, entraremos brevemente en la situación actual, para definir en qué consiste la desafección y cómo se ha producido. Como lo estamos sufriendo todos los días, no hará falta detenernos demasiado en este análisis.

A continuación, deberemos enfrentarnos, una vez más, a la intencionada definición de lo posible y lo imposible derivada del realismo político. Solo si tenemos claro que la realidad llamada democracia es la suma entre lo que hay y lo que debería haber, podemos pensar alternativas. Para hacerlo necesitamos de la ética y también de la antropología.

En tercer lugar, introduciremos la sociedad civil a partir de la idea de una democracia de doble vía, donde la democracia se entiende desde la complementación entre el estado y la sociedad civil. Habermas será nuestro punto de partida, pero una renovada ética del discurso en la que viene trabajando nuestro grupo de investigación de las universidades de Valencia y Castellón, puede ampliar los estrechos márgenes de actuación que Habermas reconoce a la sociedad civil.

Por último, se esbozará una propuesta de estructuración institucional de la sociedad civil, una sociedad civil global capaz de recuperar la fuerza inherente al mundo de la vida y dar cuenta de nuestras capacidades para actuar, para intervenir. Capacidades que, por cierto, tienen un carácter universal.

\section{La desafección como punto de partida}

Repasando un colectivo bien interesante para comprender las aportaciones de las neurociencias a la teoría democrática, El efecto de los afectos, uno se da cuenta de algo que implícitamente conocemos, pero que a veces nos cuesta 
explicitar y verbalizar ${ }^{3}$. Todos sabemos qué significa estar falto de afecto, vivir bajo la indignación y el menosprecio de los que nos rodean. Somos vulnerables, especialmente los seres humanos y, de hecho, la antropología nos enseña que la función básica de la moral es, precisamente, la protección frente a nuestra extrema vulnerabilidad ${ }^{4}$. Pero pocas veces pensamos que también las instituciones son vulnerables. Si sus miembros no se sienten parte de ellas, si no les tienen apego, si ni siquiera se las creen, acaban perdiendo lealtad, credibilidad y confianza y, al final, un final más o menos largo, desaparecen. Si hay alguien que no sabe de qué estoy hablando que piense en la reciente y desdichada desaparición de las Cajas de Ahorro. ¿Las recuerdan? No hace falta insistir en que la democracia es también una institución, y por lo mismo, vulnerable.

Con la palabra "desafección" nos referimos al escaso aprecio y estima que le tienen los ciudadanos a la vida política y a sus instituciones y representantes. Constituye un conjunto de sentimientos y actitudes reactivas caracterizado, por una parte, por la aceptación resignada de la democracia como la menos mala de las formas de gobierno, a la que no se quiere renunciar y, por otra, por un fuerte desapego, inhibición e incluso hostilidad, ante la gestión política y sus actores e instituciones. La política no consigue alcanzar la vitalidad y vinculación suficientes para mantener su credibilidad y, con ella, su sentido. Más bien produce indiferencia, desconfianza e, incluso, cinismo ${ }^{5}$. El famoso "todos son iguales" y la normalización de la corrupción, son buenos ejemplos. La apatía se muestra en la aparición de los niveles más bajos de participación en las principales instituciones de la representación política. Lemas como "no en mi nombre", o "no nos representan" reflejan muy bien esta actitud negativa hacia la política.

¿Cómo se ha llegado hasta aquí? Claus Offe nos habla de tres razones básicas para la desaparición de todo tipo de instituciones. Vamos a intentar aplicarlas a la situación actual de nuestra democracia, a ver qué ocurre.

La primera de ellas se refiere a la violación de los valores básicos y de las reglas de juego que definen toda institución. Los partidos políticos, recuerden, principal canal de participación democrática, se han convertido en todo lo contrario, en sistemas cerrados, dominados por unas élites políticas en total complicidad con los poderes económicos, con la consiguiente corrupción y

[3] Neumann W.R., Marcus G.E., Grigler G. y Mackuen M.. The affect Effect- Dynamics of emotions in Political Thinking and behavior, Chicago, University of Chicago Press, 2007.

[4] Cfr. al respecto los siguientes trabajos de J. Habermas Escritos sobre moralidad y eticidad, Barcelona, Paidós, 1991; Aclaraciones a la ética del discurso, Madrid, Trotta, 2000; La inclusión del otro, Barcelona, Paidós, 1999; para las aportaciones de las neurociencias, cfr. García Marzá D.,/ Feenstra R., Ética y neurociencias, Castellón, Universitat Jaume I, 2013

[5] M. Toscal. "La desafección democrática en las nuevas democracias: sus orígenes y consecuencias", así como C.Offe. "¿La desafección política como consecuencia de las prácticas institucionales? Algunas reflexiones neotocquevilleanas", ambos en R.Máiz. Construcción de Europa. Democracia y Globalización, Univ. Santiago de Compostela, 2001

THÉMATA. Revista de Filosofía, Nº52 julio-diciembre (2015) pp.: 93-109 doi: 10.12795/themata.2015.i52.05 
la puerta siempre dispuesta para pasar al sector privado; con un parlamento secuestrado por la disciplina de voto y unos candidatos provenientes de listas cerradas, elegidas por la dirección; con un sistema judicial politizado, con sus órganos de control y representación elegidos por los políticos; con unos medios de comunicación dependientes del poder de los presupuestos públicos o de la publicidad de los diferentes gobiernos; y así un largo etcétera. En suma, una auténtica y verdadera "partitocracia"6.

Algunos autores hablan de posdemocracia ${ }^{7}$, otros prefieren hablar de élites extractivas para referirse a esta connivencia entre los poderes políticos y los bancos y grandes empresas ${ }^{8}$. Expresiones que sin duda son exageradas, y poco ayudan a pensar, pero que reflejan un sentir compartido: el descrédito de los partidos políticos está minando el sistema representativo. Los ciudadanos ni se creen a sus representantes ni se fían de ellos.

Especial atención merece el caso de la corrupción, verdadero estigma de nuestro sistema político y principal fuente de desconfianza. Una somera radiografía de la situación en nuestro país nos mostraría a las claras cómo está afectando a todos los niveles de la administración y, lo más importante, la nula voluntad de los políticos de revertir la situación, más allá de aprobar códigos de ética que, como simple y burdo maquillaje, nadie piensa cumplir. La percepción de la corrupción aumenta año tras año y no vemos por ninguna parte nuevos mecanismos de control ${ }^{9}$. La corrupción, en su sentido más simple de aprovecharse del cargo público para el beneficio privado, nos lleva a dos reflexiones que tienen que ver con una ética de las instituciones aplicada a la democracia y con la necesidad de participación.

En primer lugar, el fracaso de las soluciones políticas y jurídicas, como muy bien muestran las dificultades y vacíos de la nueva ley de transparencia y la dilatación de los procesos judiciales. En la actualidad existen más de 1700 causas abiertas en los juzgados, 500 imputados y apenas veinte en la cárcel. El derecho, una vez más hay que decirlo, es necesario pero no suficiente. No solo es lento, también muchas veces ineficaz y, en especial, está hoy por hoy sometido a la colonización política.

En segundo lugar, no existe ninguna prueba que demuestre la correspondencia entre una mayor participación política y una menor corrupción. Peor aún, los mayores índices de corrupción los tenemos en las esferas locales

[6] Alonso S., "Votas pero no eliges: la democracia y la crisis de la deuda soberana en Europa", en Recerca, n.15, 2014, pp.21-55, así como Alonso S., Keane J. y Merkel W. (ed.), The Future of Representative Democracy, Cambrigde University Press, 2011

[7] Crouch C., Posdemocracia Madrid, Taurus, 2003.

[8] Acemoglu D; Robinson J.A., Por qué fracasan los países, Deusto ediciones, 2012

[9] Villoria, M.,Jiménez F. "La corrupción en España (2004-2010): datos, percepción y efectos." Revista Española de Investigaciones Sociológicas 138.1 (2012): 109-134; así como Villoría M., Ética pública y corrupción, Madrid, Tecnos, 2000

THÉMATA. Revista de Filosofía, Nº52 julio-diciembre (2015) pp.: 93-109 doi: 10.12795/themata.2015.i52.05 
y autonómicas, donde la representación es más cercana y, teóricamente, más efectiva ${ }^{10}$. De hecho, bien sabemos que la misma participación puede amenazar con volverse corrupta cuando se utiliza para conseguir poder. No es otra cosa el clientelismo político. Mal asunto para quien defienda, como el que escribe, la participación como salida a la desafección. A no ser que la participación pretendida incida en las esferas no-políticas de las que se nutre la política.

La segunda razón de la desafección, seguimos con Offe, tiene que ver con la eficacia del sistema, con los resultados que se esperaban obtener de la institución llamada democracia. Ahora, a la desconfianza en los políticos se suma la frustración ante sus políticas, en el marco, no lo olvidemos, de una democracia como la española, entendida desde las coordenadas de un Estado Social y Democrático de Derecho. A diferencia de la crisis de los años setenta, no hablamos de las dificultades para alcanzar las expectativas -siempre elevadas- del estado de bienestar, sino del incumplimiento de los mínimos de justicia que garantizan la dignidad de las personas y, por ende, una ciudadanía democrática ${ }^{11}$.

Ejemplos tenemos en el insoportable nivel de desempleo, en especial los jóvenes (53\% frente al $12 \%$ de media en la UE); en la precarización de las condiciones laborales; en el incremento de los niveles de pobreza junto con la concentración de la riqueza en pocas manos; en el abandono actual de los más vulnerables a su suerte; en el drama de los desahucios; en la ruptura de la igualdad de oportunidades en educación y sanidad, etc. Solo es necesario remitir al VII Informe sobre Exclusión y Desarrollo Social en España, realizado por la Fundación Foessa y auspiciado por Cáritas, para comprobar cómo está aumentando la pobreza, la desigualdad y la exclusión en nuestro país.

De tres razones, ya cumplimos dos. La tercera, nos dice Offe, es la aparición de alternativas que "se perciben" mejores. El populismo es ya una realidad, precisamente como respuesta al "no nos representan". Los partidos políticos, el actual gobierno a la cabeza, saben muy bien que es más fácil - y más ventajoso- manipular el lenguaje y engañarnos que cambiar una realidad claramente injusta. Aparece entonces el recurso al miedo o a las palabras vacías que a nada comprometen. Hay que prepararse contra el populismo que hoy caracteriza, en mayor o menor grado, a todos los partidos.

La situación descrita sería para terminar ahora este artículo si no fuera porque al mismo tiempo que asistimos a esta desafección, asistimos también a un fuerte dinamismo participativo. La falta de interés, de compromiso y parti-

[10] Warren M.E., "La democracia contra la corrupción." Revista Mexicana de Ciencias Políticas y Sociales 47.193, 2005

[11] Cfr. Para la crisis del estado de bienestar, Habermas J., Problemas de legitimación del capitalismo tardío, Buenos Aires, Amorrortu, 1973; para la diferencia entre estado de bienestar y estado de justicia Cortina A. Hasta un pueblo de demonios. Ética pública y sociedad, Madrid, Taurus, 1998

THÉMATA. Revista de Filosofía, No52 julio-diciembre (2015) pp.: 93-109 doi: 10.12795/themata.2015.i52.05 
cipación en los asuntos políticos, va acompañada del aumento de todo tipo de iniciativas, de plataformas y movimientos ciudadanos; de la proliferación de manifestaciones y acciones colectivas de protesta; del incremento del número y la fuerza de las organizaciones solidarias; de la creación de nuevas asociaciones para la defensa de intereses ya sean comunes ya sean generales; etc. En suma, de nuevas e innovadoras formas de participación fuera de las estructuras del sistema representativo.

Se revitaliza así una sociedad civil que el mal llamado estado del bienestar había adormecido. Ahora la participación se realiza de forma espontánea, centrada en causas concretas, con un fuerte compromiso moral y asentadas en espacios públicos donde la relación personal es aún posible. Acciones ancladas en los contextos del mundo de la vida, directamente relacionadas con nuestros intereses, nuestro trabajo, nuestra salud, nuestras familias, etc ${ }^{12}$.

La fuerza y aceptación de movimientos como el 15M; el éxito de la marea blanca con la implicación de los profesionales sanitarios; de las plataformas antidesahucios; de la vigilancia y monitorización en las redes, etc. ${ }^{13}$ muestran a las claras una conclusión bien simple que, esta vez sí, debe ser el punto de arranque para una ética de la democracia: la desafección afecta básicamente al sistema representativo y a los partidos políticos, en suma, a la democracia como institución política. Pero no a la democracia como forma de sociedad, de organizar una vida en común.

Una clara lección para dejar de confundir democracia y representación. La sociedad civil no es sociedad política, pero es una parte decisiva de la democracia. No todas las relaciones sociales son relaciones políticas, pero si en ellas se dan relaciones de poder y deben resolverse conflictos desde una voluntad común, deben formar parte de una democracia, sean empresas, universidades, hospitales o iglesias. Es hora de ampliar el concepto de democracia, de recuperar el valor de la sociedad civil. ¿Es esto fácticamente posible?

\section{La realidad manda: de nuevo el realismo político}

Para responder afirmativamente, en nuestro caso para identificar el potencial de la sociedad civil, es necesario desarticular uno de los tópicos más recurrentes en la historia de la teoría democrática. Me refiero al realismo político. Un argumento en el que se dan por zanjadas muchas discusiones con una simple afirmación: así son las cosas y nada se puede hacer. Esta imposibilidad interesada, por así decirlo, es una constante en el lenguaje actual de nuestros políticos. Al escribir estas páginas tuve ocasión de leer las siguientes declara-

[12] Hirst, P., Associative democracy: new forms of economic and social governance. John Wiley \& Sons, 2013

[13] Feenstra R.,/ Keane J., "Politics in Spain: A case of Monitory Democracy”, Voluntas, 25, 2014, pp. $1262-1280$.

THÉMATA. Revista de Filosofía, No52 julio-diciembre (2015) pp.: 93-109

doi: 10.12795/themata.2015.i52.05 
ciones de un líder empresarial: "el drama humano es muy duro, pero la realidad manda y es mucho más dura", para argumentar - no es una broma- que son los empleados los que deberían indemnizar a la empresa por darles trabajo ${ }^{14}$.

Las posiciones realistas son bien conocidas y parten de que la participación política solo se mueve por un individualismo egoísta, por la defensa y satisfacción de nuestros propios intereses o preferencias. Si a este monismo motivacional le sumamos la complejidad de los temas políticos y la falta de conocimiento y tiempo para resolverlos -nos dicen-, no hay más remedio que reducir la participación a votar periódicamente y, después, dejar los asuntos públicos en manos de los políticos profesionales. La democracia en este sentido, no es más que un procedimiento para la elección de representantes, presuntos líderes, que competirán entre ellos para alcanzar el gobierno, igual que se compite en el mercado. La razón última de elitismo no es otra que, como hace años afirmaba Schumpeter, "el ciudadano normal desciende a un nivel inferior de prestación mental tan pronto como penetra en el campo de la política"15. Sin comentarios.

Esto es lo que hay, cualquier otra posición es calificada de idealismo, o, mejor, de utopismo. Sartori, por ejemplo y precisamente ante el parlamento español, no dudó en calificar de "ignorancia y primitivismo democrático", de "niños que juegan con pensamientos infantiles", todo intento de ir más allá de la democracia representativa actual ${ }^{16}$.

Sin embargo, otros pensamos que no hay posibilidad alguna de superar la desafección, de pensar un futuro democrático mejor, si no vamos más allá de la democracia meramente representativa. Y para ello debemos, una vez más, desmentir las recurrentes premisas del realismo político. Repasemos brevemente tres de estos prejuicios que, a base de repetirlos, han perdido el prefijo, se han convertido en juicios irrefutables sobre la realidad.

La primera premisa que debemos desmentir es el individualismo metodológico que sostiene este falso realismo. La ingenuidad de pensar que primero son los individuos y luego la sociedad creada por un contrato, ya fue denunciada por Hegel. Pero es en la antropología de Mead donde encontramos una relación más próxima con el saber moral. Textualmente nos dice Mead: "de un lado, está la sociedad que hace posible a la persona, y del otro lado, se encuentra la persona que hace posible a la sociedad altamente organizada. Ambas se responden mutuamente en la conducta moral"17.

[14] Diario Público, Madrid, 27-3-2014

[15] Schumpeter, J. A. Capitalismo, socialismo y democracia, Madrid. Folio, 1996, p. 336

[16] Sartori G., "En defensa de la representación política." Claves de Razón Práctica 91, 1996, pp: 2-6

[17] Mead G.H., Espíritu, persona y sociedad, Paidós, Barcelona, 1982, p.386; cfr.para este argumento García Marzá D.,Teoría de la democracia, Valencia, Nau, 1993

THÉMATA. Revista de Filosofía, N ${ }^{\circ} 52$ julio-diciembre (2015) pp.: 93-109 doi: 10.12795/themata.2015.i52.05 
Es la intersubjetividad el punto de partida, no la individualidad. Si los intereses están socialmente construidos, no podemos partir del individuo como un actor aislado y autosuficiente, ni tampoco de la sociedad como un actor colectivo, debemos hacerlo de la relación entre ellos, de la comunicación que posibilita esta interrelación. Desde este punto de partida, la democracia no tiene tanto que ver con el equilibrio o agregación de intereses privados, sino con la participación, la deliberación y la búsqueda de acuerdos que nos permita definir, en caso de conflicto, "intereses más amplios", con los que nos podamos identificar.

La segunda premisa se refiere a la antropología negativa que subyace a este realismo. Se sigue haciendo oído sordo a argumentos como los de Sen en su famoso artículo "los tontos racionales", donde muestra, que no solo somos capaces de conductas autointeresadas, sino también de compromisos. Como muy bien ha mostrado entre nosotros Jesús Conill en su lectura de Aristóteles, Smith y Sen $^{18}$.

Tenemos múltiples disposiciones y capacidades, y la conducta egoísta es una de ellas, pero no la única y si nos paramos a pensar un poco, tampoco la más importante. ¿Cuántas cosas hacemos al día que nada tienen que ver con la maximización de utilidades, con la oferta y la demanda, con la estrategia y el intercambio de equivalentes?

Pero de nuevo la antropología en su vertiente evolutiva está proporcionado argumentos bien interesantes. Por ejemplo Tomasello, tanto en su obra ¿Por qué cooperamos?, como en trabajo más reciente "El animal ultra-social", muestra como lo más remarcable de la evolución humana, es nuestro comportamiento pro-social, nuestras variadas y diversas formas de cooperación, así como la importancia de los valores y normas que las regulan ${ }^{19}$.

Pero quizás, y para no cansarles más, sirva como resumen de este argumento contra el realismo antropológico, recordar unas sencillas palabras de Kant cuando, ya en su tiempo, se le criticaba el idealismo de toda posición que no fuera la "realmente existente". Hay que tomar a los hombres como son y no como los soñadores, poetas y filósofos creen que deberían ser, le dicen a Kant. A lo que responde de forma sencilla y magistral: "Los hombres como son significa los hombres tal y como los hemos hecho" ${ }^{20}$. De ahí la importancia de la

[18] SEN, A. "Los tontos racionales: una crítica de los fundamentos conductistas de la teoría económica”, en Filosofía y Teoría Económica, México, FCE, 1986, 172-216; Conill J., Horizontes de economía ética, Madrid, Tecnos, 2003

[19] Tomasello M., "The ultra-social animal”, European Journal of Social Psychology, 44,187194, 2014; así como ¿Por qué cooperamos?,Barcelona, Katz, 2010; así como Pierpaolo D.,/ Calvo P., (eds.) New insights into relational goods, Recerca. Revista de Pensament i Anàlisi nº 14, 2014.

[20] Kant I, "Idea de una historia universal en sentido cosmopolita" (1784), en Filosofía de la historia. México: FCE, 1981, 39-65; para la importancia de una educación moral y cívica que tenga en cuenta los sentimientos y emociones Cortina A., Ética de la razón cordial: educar en la ciudadanía en el siglo XXI, Oviedo, Nobel, 2007.

THÉMATA. Revista de Filosofía, No52 julio-diciembre (2015) pp.: 93-109 doi: 10.12795/themata.2015.i52.05 
educación, de ahí que sean sus instituciones lo primero que quieran "controlar" nuestros políticos.

La tercera premisa que sostiene al realismo político reaparece con toda su fuerza con las neurociencias. Si bien éstas nos permiten desvelar la falsedad del homo economicus, también nos traen una nueva versión del colonialismo e imperialismo cientificista, esto es, la enésima vuelta del positivismo, si es que alguna vez se ha ido. Para hablar de verdad y, con ello, para hablar de lo posible y lo imposible, solo vale la metodología de las ciencias naturales: observación, hipótesis, verificación. Solo valen los hechos, solo valen los datos. Frente a esta nueva oleada, debemos también insistir una y otra vez en que este -por decirlo con Apel- "pragmatismo de lo real posible" no es más que la confusión entre la realidad natural y la realidad social presupuesta en toda pretensión cientificista. Veamos en qué sentido.

La realidad social la construyen las personas, no es una realidad independiente de lo que pensamos y hacemos, sino su resultado. Si nos equivocamos sobre la gravedad no podremos construir aviones, pero la gravedad seguirá siendo la misma. Si nos equivocamos sobre la democracia y la confundimos con el populismo, al final será populismo lo que tendremos. No puede haber la misma metodología para acercarnos a dos realidades tan diferentes. En cualquiera de los saberes prácticos, reducirnos a los hechos significa sencillamente renunciar a toda posibilidad de cambio y transformación social. Es decir, resignarnos a la injusticia ${ }^{21}$.

Como cualquier institución, la democracia real es la unión entre lo que hay, lo existente, y los conceptos que se usan para legitimar lo existente ${ }^{22}$. Ideas y valores que cristalizan en las diferentes prácticas y en las instituciones en las que se apoyan. La democracia tiene su legitimidad anclada en la idea moral de autonomía, en la capacidad de participar y decidir por nosotros mismos, de no consentir leyes que no hayamos aprobado o dado permiso para hacerlo. Esta idea constituye un saber real, una razón situada, y puede convertirse en un recurso, en un capital para vencer la desafección.

El realismo político es mentira. Es falso que no podamos ni siquiera defender, con criterios intersubjetivos de validez, posibilidades alternativas. Podemos pensar "otra" democracia porque tenemos otras capacidades que deben reconocerse y poseer su espacio de acción, su institucionalización. Una democracia hacedera, diría Aranguren, una democracia posible. Para este fin, debemos rebajar el valor de la representación a lo que realmente es: una técnica para la toma de decisiones políticamente vinculantes. Veamos cómo.

[21] Cfr. Al respecto García Marzá D., "Neuropolítica”, en Cortina A., (ed.), Neurofilosofía práctica, Granada, Comares, 2013, pp.77-97

[22] Cortina A., Ética aplicada y democracia radical, Madrid, Tecnos, 1993.

THÉMATA. Revista de Filosofía, Nº52 julio-diciembre (2015) pp.: 93-109 doi: 10.12795/themata.2015.i52.05 


\section{Democracia de doble vía}

Desde la perspectiva ética la democracia no puede reducirse a la agregación de intereses dados e inmodificables, ajenos a nuestra voluntad, sencillamente porque de esta forma se desprecia nuestra autonomía, nuestra capacidad para deliberar, convencernos y cambiar nuestros intereses. Una autonomía expresada en nuestro lenguaje moral cotidiano, que nos permite hablar de intereses equivocados, de criticar con razones las decisiones tomadas por nuestros representantes aunque sean mayoritarias. La mayoría no implica verdad, ni mucho menos justicia. Bien claro está cuando nos remitimos a la injusticia de determinadas agregaciones que dejan "fuera" a una parte de los ciudadanos, o cuando pensamos en la herencia que estamos dejando a las futuras generaciones. Una teoría de la democracia no puede ignorar este saber moral, estas capacidades o recursos, este capital ético.

Este es el germen de las denominadas democracias deliberativas, una serie de teorías que entienden que la deliberación pública de ciudadanos libres e iguales es la clave de la legitimidad del proceso político, que reconocen la existencia de un núcleo moral en la base de toda posible legitimación y que entienden la democracia, como diría Carlos Nino, como un poder para transformar los intereses de la gente de un modo moralmente aceptable. Y este poder no se logra sin la participación libre e igual de todos los afectados ${ }^{23}$.

En el interior de este núcleo aparece la participación como exigencia moral derivada de la autonomía y, con ella, también los problemas para entender esta propuesta de una nueva democracia participativa. Desde el punto de vista moral se exige la participación real y efectiva de todos los afectados, pues no hay otra forma de hablar de justicia sino es desde el acuerdo libre e igual de todos los implicados. Desde el momento en que el proceso político no considera las preferencias e intereses como algo dado sino que pueden transformarse discursivamente, nunca puede delegarse la responsabilidad, es decir, la posibilidad de participar para cambiar nuestros propios intereses. La participación que se exige es real, directa y efectiva.

Mira por donde, huyendo del realismo caemos de lleno en su crítica de idealismo. Pues un mínimo sentido común nos dice que tal participación es fácticamente imposible. De hecho no hay teoría democrática alguna que identifique hoy democracia con democracia directa o plebiscitaria.

Las democracias participativas -recuerden a Macpherson, Bachrach, Pateman, etc.- partieron de estas ideas y propusieron ampliar

[23] Cfr. Para la democracia deliberativa Habermas J., La inclusión del otro, Barcelona, Paidós, 1996; Nino C., La constitución de la democracia deliberativa, Barcelona, Gedisa, 1997; Bohman J., Rehg W.(eds.), Deliberative Democracy, Cambridge, MIT press, 1999; Elster J., La democracia deliberativa, Barcelona, Gedisa, 2001; Gutmann A., Thompson D., Why deliberative democracy?, Princenton University Press, 2004.

THÉMATA. Revista de Filosofía, No52 julio-diciembre (2015) pp.: 93-109 doi: 10.12795/themata.2015.i52.05 
la política a las esferas donde existe poder, a sectores como, por ejemplo, la empresa, con la llamada democracia industrial, y fracasaron. Tampoco ganamos nada hoy reduciendo los temas a debatir o los espacios y posibilidades de participar. Vuelve a originarse el problema del elitismo, esta vez deliberativo, de quién representa a quién y por qué. El resultado es que hoy la participación no tiene muchos defensores, parece haber perdido toda fuerza de convicción ${ }^{24}$.

Los trabajos de Habermas sobre política deliberativa nos permiten pensar una solución a esta situación donde lo deseable no es posible y lo posible es claramente injusto. Nos interesa porque, a mi juicio, nos permite refutar la falsa identificación entre democracia y política. En su propuesta, la democracia se entiende como un modelo de doble vía, un modelo dual en el que la idea de sociedad civil va a tener un lugar prominente, precisamente como suelo para la opinión pública, para una publicidad encargada de los intereses generalizables. Como espacio ético, añadiría por mi cuenta.

La metodología que utiliza Habermas para su propuesta, es de tipo reconstructivo, trascendental con todos los adjetivos que se quieran, y consiste, según sus palabras: "mostrar qué es lo que tácitamente estamos suponiendo siempre ya en lo tocante a contenidos normativos cuando participamos en esas prácticas democráticas"25. De forma más fácil, se trata de sacar a la luz una razón situada, un saber presupuesto en la comprensión que, como ciudadanos, como participantes, tenemos de la democracia. Si somos capaces de acceder a este saber, a lo que pensamos que debería ser la democracia y, por tanto, a lo que esperamos de ella, estaremos en posesión de un estándar crítico con el que juzgar las prácticas de la realidad democrática y orientar posibles alternativas. La teoría no tiene que describir, ni prescribir, debe más bien explicitar -reconstruir- el sentido que los implicados y afectados por los procesos democráticos tienen de su participación.

El resultado de esta metodología es la comprensión del proceso político como una red de discursos y negociaciones que incluye: discursos pragmáticos (cómo alcanzar lo que queremos), discursos ético políticos (lo que queremos ser como colectivo); negociaciones y compromisos ( acuerdos entre intereses particulares); discursos morales (establecen los criterios de justicia para todos los demás discursos) y discursos jurídicos (encargados de convertir en leyes los resultados de la formación de la voluntad política). En este sentido, el estado democrático de derecho constituye para Habermas la institucionalización jurídica de esta red de

[24] García Marzá D., "Un modelo deliberativo de democracia participativa”, Arbor, 608, 1996, pp. 97-121; así como "Política deliberativa y sociedad civil: el valor actual de la participación", en J. Conill / D. A. Crocker (eds.) Republicanismo y educación cívica, Granada, Comares, 2003, pp.111. 135.

[25] Habermas J.,Más allá del estado nacional, Madrid, Trotta, 1997,p.143ss.

THÉMATA. Revista de Filosofía, Nº52 julio-diciembre (2015) pp.: 93-109 doi: 10.12795/themata.2015.i52.05 
discursos y negociaciones, de las condiciones de comunicación y procedimientos que la hacen posible ${ }^{26}$.

Es imposible entrar en estas breves líneas en el análisis de este saber intuitivo que realiza Habermas en Facticidad y Validez, pero sí extraer tres conclusiones del mismo que afectan a nuestra comprensión de una democracia participativa actual y que en otros lugares me he permitido argumentar ${ }^{27}$.

Primera conclusión importante, recordando de nuevo a Kant, no hay política sin ética. Los discursos morales están incrustados en nuestra competencia como ciudadanos y se refieren a la justicia de una práctica determinada. Aquí se discuten las decisiones, normas, compromisos, agregaciones, etc., siempre desde el punto de vista de la capacidad de generalización de intereses, de "aquello que es bueno para todos". Un todos que incluye a todas las personas implicadas en su calidad de interlocutores válidos ${ }^{28}$.

Permítanme un ejemplo de la existencia y significación de este saber moral incrustado en el día a día de la democracia. Si nos fijamos en el movimiento de los indignados, veremos cómo su fuerza y su poder de convicción no dependen del incumplimiento de unos programas políticos u otros, sino del incumplimiento de unos mínimos de justicia, unos mínimos que posibilitan hablar de "dignidad". Es el núcleo moral de la democracia el horizonte de actuación y la base argumentativa y motivacional del dinamismo participativo al que antes hacíamos mención. Por cierto, sea cual sea el contexto cultural en el que se mueva.

Segunda conclusión importante para nuestro esfuerzo por reconocer el valor de la sociedad civil: la consideración meramente instrumental, técnica, del sistema representativo. A juicio de Habermas, no existe dicotomía alguna entre democracia plebiscitaria y democracia representativa, pues el resultado de la red de discursos descrita siempre debe quedar con una reserva falibilista. Si la participación no puede delegarse, puesto que todos deben deliberar, toda solución alcanzada resta, nos dice Habermas, "permeable, sensible y abierta a intervenciones, razones e informaciones que llegan de un espacio público que tiene su base en la sociedad civil ${ }^{29}$.

Dicho de otra forma, el respeto a la "igual participación" exige que haya una apertura de los mecanismos representativos (parlamento, concurrencia de partidos, sufragio universal, regla de mayorías, etc.) a la influencia de la opinión

[26] Habermas J.,Facticidad y validez, Madrid, Trotta, 1998, p.225ss.

[27] García Marzá D., "Ética de la democracia”, en Quaderns de Fiosofia i Ciència. 25/26, 1995, pp.181-187.

[28] García Marzá D., “Todos sin ser todos deciden...”: democracia y publicidad en Kant”, en Andaluz Romanillos A.M.,(Ed.), Kant. Razón y experiencia, Salamanca, 2005.

[29] Habermas J.,Facticidad y validez, p. 251.

THÉMATA. Revista de Filosofía, No52 julio-diciembre (2015) pp.: 93-109 doi: 10.12795/themata.2015.i52.05 
pública como voz de los intereses generalizables, esto es, del punto de vista mo$\mathrm{ral}^{30}$. La opinión pública se convierte así en el suelo de resonancia que aporta los problemas básicos que deben ser gestionados por el sistema político, en un espacio donde se configuran comunicativamente las expectativas legítimas y se vigila y controla su traducción y realización políticas. Pero no debemos confundir la opinión pública con la opinión publicada, como a continuación veremos.

Tercera conclusión importante: la necesidad de la sociedad civil como base social de la opinión pública. Aquello que define la fuerza de la opinión pública no es su carácter representativo, la cantidad de opiniones recogidas en sondeos, encuestas, etc., sino su calidad. Una calidad que responde al modo en cómo se ha producido, esto es, a su proceso de formación. De ahí la necesidad de un espacio social propio donde sea posible esta participación libre de dominación, donde la solidaridad y el entendimiento sean los mecanismos básicos de comunicación, es decir, donde reine la acción comunicativa. A juicio de Habermas, este es el papel de la sociedad civil, alejada del medio poder y del medio dinero ${ }^{31}$.

Con esta propuesta de una democracia de doble vía, de complementación entre el estado y la sociedad civil, la participación que exige el proceso democrático no se reduce a la participación política, sino que se extiende necesariamente a todas las esferas de la sociedad civil, como bien muestra la consideración de la desobediencia civil como participación democrática ${ }^{32}$.

En mi opinión, si bien con esta introducción de la sociedad civil conseguimos garantizar la perspectiva crítica y valorar la representación como una cuestión técnica, esta base sociológica de la opinión pública está demasiado alejada de la realidad en esta interpretación habermasiana, puesto que deja "fuera" del concepto todos los espacios de acción y sus respectivas instituciones que no se orienten exclusivamente a través de la solidaridad y del entendimiento. Fuera de la sociedad civil se ha quedado así el ámbito de los mercados y de las empresas, al igual que el resto de esferas que impliquen desigualdad y relaciones asimétricas de poder. Precisamente los ámbitos donde se origina y se desarrolla el poder. De ahí que una ética de la democracia, necesite ampliar este concepto de sociedad civil, si quiere enfrentarse a la actual desafección. Este va a ser nuestro próximo y último punto.

\section{El valor de la sociedad civil: de nuevo la participación}

A pesar de la ambigüedad del concepto de sociedad civil, auténtica sopa de pollo dicen los ingleses donde cabe todo tipo de ingredientes, si seguimos hablando de una revaloración del concepto es precisamente por la necesidad de

[30] Ibidem, p. 439 .

[31] Ibidem, p.447.

[32] Cfr.al respecto García Marzá D., "Desobediencia civil”, en Cortina A., Diez conceptos clave en Filosofía política,, Madrid, EVD, 1996.

THÉMATA. Revista de Filosofía, N ${ }^{\circ} 52$ julio-diciembre (2015) pp.: 93-109 doi: 10.12795/themata.2015.i52.05 
superar la actual desafección, derivada de la reducción de la democracia a la representación política. La doble vía nos permite pensar de nuevo la democracia como un tipo de sociedad y no solo como un régimen político, como un modo de resolver los desafíos y conflictos de toda convivencia.

Las democracias deliberativas han seguido con esta idea de la democracia de doble vía. A la segunda generación de autores como Bohman o Dryzek ${ }^{33}$. preocupados ya por la viabilidad de las propuestas normativas iniciales, le ha seguido una tercera generación de estudios sobre la democracia deliberativa, con un marcado carácter descriptivo. En estos desarrollos, el papel de la sociedad civil puede resumirse en dos posiciones:

-Enfoques micro que trabajan con minipúblicos, foros deliberativos estructurados que pueden engancharse, "vincularse", con la política deliberativa. Presupuestos participativos, foros y consejos ciudadanos, de discusión, etc.

-Enfoques macro que trabajan con el papel de la sociedad civil como opinión pública "fuera" y "frente" al estado, y que van desde los movimientos sociales hasta el periodismo ciudadano.

A mi juicio, una de las ventajas de este, así llamado, "giro empírico" de las democracias deliberativas es haber descubierto la importancia de los entornos o contextos institucionales. Mostrando, por ejemplo, que aquellos que se declaran más proclives a deliberar son los que más se apartan de las políticas partidistas. Pero también destacan los mismos trabajos la precariedad de estos logros, su mínima expresión e importancia en un mar de complejidades. Por no hablar del elitismo que supone elegir a determinados sujetos para discutir determinadas cuestiones, en contextos separados de la realidad ${ }^{34}$.

Pero estas concreciones de las propuestas deliberativas no consiguen, a mi juicio, el objetivo de ampliar la democracia representativa, precisamente por seguir aceptando la división tajante entre sistema y lebenswelt. Como si las empresas o, incluso, el medio dinero, no fueran acuerdos sociales que necesitaran del contexto del mundo de la vida para tener validez y, por lo tanto, vigencia. Al excluir estas esferas de su análisis consiguen visibilizar el poder de la sociedad civil pero siempre con referencia al estado, como "un segundo circuito de la política". No ven el valor que tiene la sociedad civil en sí misma ${ }^{35}$. Recordemos que en nuestro idioma, valor significa tanto importancia como fuerza. Para contrarrestar la desafección hay que salir de esta dicotomía

[33] Bohman J.,Public deliberation: Pluralism, complexity, and democracy. MIT press, 2000; Dryzek J.S. Deliberative global politics: Discourse and democracy in a divided world. Cambridge: Polity, 2006.

[34] Hendriks, C.M.,"Integrated deliberation: Reconciling civil society's dual role in deliberative democracy", Political studies, 2006, 54.3: 486-508.

[35] García Marzá D., "Democracia de doble vía: el no-lugar de la empresa en la sociedad civil", Revista del CLAD Reforma y Democracia, n 57, octubre 2013, pp: 67-92; así como García Marzá D., “Responsabilidad social de la empresa: una aproximación desde la ética empresarial”, Veritas: revista de filosofía y teología, 2007, pp.183-204.

THÉMATA. Revista de Filosofía, No52 julio-diciembre (2015) pp.: 93-109 doi: 10.12795/themata.2015.i52.05 
entre acción comunicativa y acción estratégica y aprender a pensar qué integración de ambas lógicas merece validez moral. En mi opinión, la perspectiva ética nos permite salir de esta prisión conceptual y visibilizar el poder de la sociedad civil en toda su amplitud. Una búsqueda de espacios donde realizar el abanico de disposiciones que caracteriza a este ser ultra-social que somos las personas, entre ellas nuestros recursos morales.

Mi propuesta parte de esta concepción dual de la democracia, destacando el valor de la sociedad civil y centrándose en su estructura institucional, en la aportación de la ética al diseño institucional. La fuerza y el poder de la sociedad civil derivan de su voluntariedad y espontaneidad, de la imposibilidad de delimitar sus fronteras y encerrarlas en la lógica del poder político o económico. Este poder es el que nos interesa ${ }^{36}$.

Si fijamos nuestra atención en las instituciones que sustentan las distintas esferas de la sociedad civil, tenemos un anclaje posible para la participación y el desarrollo de la autonomía. Instituciones entendidas aquí como acuerdos sociales estables y legítimos, encargados de proporcionar bienes sociales básicos como la paz y la seguridad, la educación, la salud, la eficiencia, etc. Esta es la función de la escuela y o la universidad, del hospital o la empresa, etc. De hecho, es imposible negar el poder que tienen estas instituciones y, por consiguiente, rechazar que tengan un papel clave en nuestra democracia, que sean parte de la misma. Una ética de la democracia puede aportar su granos de arena para definir estos nuevos espacios de participación en un doble sentido:

-Por una parte, la ética puede contribuir al diseño y rediseño de instituciones aportando los principios básicos para que la participación de todos los implicados o afectados sea posible en su interior. Por supuesto, en la mayoría de las veces se requiere la representación, pero ajustada a la lógica propia de cada una de las prácticas sociales, no repitiendo en su seno la lógica política.

-Por otra parte, es importante que las actuales iniciativas que surgen de la sociedad civil no se pierdan en la inmediatez de los problemas, que puedan alcanzar diferentes grados de estabilidad. No es necesario ni conveniente que todo el dinamismo participativo del que hemos hablado acabe en los partidos políticos. Al contrario, yo creo que este ha sido el error que nos ha conducido a la actual colonización política, a la actual partitocracia.

El poder se encuentra distribuido en las distintas esferas sociales y debemos aprender a gestionarlo integrando el saber moral en el funcionamiento propio de cada una de ellas. Que podamos hablar de la estructuración democrática de un hospital no significa que los pacientes voten cómo han de ser las operaciones quirúrgicas, significa que encontremos espacios

[36] García Marzá D., "Sociedad civil: una concepción radical”, Recerca, , nº, 2008, pp: 27-47.

THÉMATA. Revista de Filosofía, №52 julio-diciembre (2015) pp.: 93-109 doi: 10.12795/themata.2015.i52.05 
de participación de todos los grupos de intereses en su interior, dentro del hospital. Significa que los pacientes puedan influir en la marcha del hospital, más allá de los servicios de información y atención al paciente.

Una ética de las instituciones tendría así como objetivo establecer principios para el diseño institucional que definieran la participación de cada uno de los grupos de interés en el interior de las instituciones ${ }^{37}$. Espacios públicos de participación dentro de las instituciones, ya sean como comités de ética, consejos escolares, comités de bioética asistencial y clínica, comisiones de responsabilidad corporativa, etc. Espacios que potenciaran tanto el seguimiento y control directo, como la influencia de la opinión pública. En suma, espacios capaces de combinar los enfoques micro y macrodeliberativos.

De esta forma conseguimos ampliar el horizonte de la democracia respetando la peculiaridad de cada una de estas esferas, tarea que requiere de una hermenéutica crítica, anclando de nuevo la participación en el mundo de la vida. Ya no se trata de programas y propuestas complejas y a largo plazo, sino de un poder directo, dentro de un contexto cultural, de unos valores, de unas identidades. Las mismas personas que no se movilizan por la sostenibilidad medio ambiental, sí lo pueden hacer para evitar un vertedero industrial en su municipio. Integrando objetivos prácticos muy concretos con objetivos morales, el interés general con el interés colectivo o, incluso, particular, podemos recuperar la vitalidad perdida.

Desde esta doble vía es factible reivindicar de nuevo las pretensiones de una democracia participativa. En primer lugar, porque entiende que la participación política es necesaria, pero es solo una forma de participar, nunca puede sustituir a la participación civil. Y, en segundo lugar, a diferencia ahora de los modelos deliberativos, porque entiende que participar no es solo deliberar. También es decidir, protestar, negociar, colaborar, etc. Al situarnos en los contextos cotidianos no se separa el lenguaje de la solidaridad del de la eficacia; no puede hablar de compromiso sin hablar de "sentirse bien", de conseguir objetivos a través de actividades plenas de sentido, gratificantes.

Desde esta diversidad de recursos y capacidades que caracteriza a las personas, la sociedad civil va mucho más allá de la función crítica que le reconocen los enfoques deliberativos. Para Habermas, la sociedad civil solo tiene influencia, no tiene poder. Su meta es influir en el sistema político, acabar convirtiéndose en derecho ${ }^{38}$. Mala solución, diría yo, si nos fijamos como ya hemos dicho, en la eficacia del derecho penal en los casos de corrupción. Pero peor solución aún si nos detenemos a pensar en los problemas actuales, la mayoría de carácter global, con

[37] García-Marzá, D."La dimensión ética del diseño institucional” en González Esteban, Elsa (ed.) Ética y Gobernanza: un cosmopolitismo para el siglo XXI, Comares, Granada, 2013, pp. 31-58. [38] García Marzá D., "El poder de la sociedad civil: hacia una ética de la instituciones”, Debats, vol.4, núm. 109, 2010,pp. 30-38.

THÉMATA. Revista de Filosofía, N52 julio-diciembre (2015) pp.: 93-109 doi: 10.12795/themata.2015.i52.05 
interdependencias que se le escapan al marco jurídico del estado nación. La sociedad civil debe aprender a hacer uso de sus recursos para solucionar por sí misma los retos de toda actuación conjunta. Y esto es posible si entendemos la sociedad civil desde tres rasgos básicos. Veamos, ya para terminar, en qué consisten.

Debe ser plural porque en los ámbitos de la sociedad civil nos encontramos con intereses particulares (prestigio, dinero, etc.), lo mismo que con intereses colectivos (profesionales, corporativos, de regulación de actividades comunes, etc.) y con intereses generales o universales (reconocimiento, dignidad, etc.). También en esta propuesta de comprensión de la sociedad civil, el ámbito moral se identifica con los intereses generalizables, pero no se reduce a él. La acción comunicativa debe integrarse con la acción estratégica. El grado de integración conseguido define la moralidad alcanzada y, con él, la capacidad de generar confianza. Esa es la diferencia entre una buena y una mala sociedad civil.

Debe ser radical porque incluye, en primer lugar, a todas las instituciones que conforman esta esfera, sean económicas, sociales o culturales; y, en segundo lugar, porque incluye a todos los implicados y afectados por la actividad de estas instituciones. El criterio de legitimación y, por lo tanto, la validez moral, el horizonte de actuación, no es otro que el acuerdo posible de todos los implicados en condiciones simétricas de participación. Solo desde este horizonte es posible hablar de representación.

Debe ser global porque exige la participación y el acuerdo sea cual sea la extensión de los problemas o de las instituciones creadas para su resolución. De esta forma escapa al estatismo metodológico al contar con sus propios mecanismos de coordinación de la acción, derivados de la capacidad de establecer acciones comunicativas y los compromisos morales que implican. Las fronteras de la sociedad civil, sus límites, vienen determinados solo y exclusivamente por la dimensión de los conflictos que se quieren solucionar de forma dialógica y razonada. Esto es lo que significa universalismo, el reconocimiento del necesario diálogo intercultural.

Con en esta propuesta de una democracia de doble vía, la participación deriva de la exigencia moral del respeto igual de todos los intereses en juego y recorre todas las esferas como una capacidad o recurso para generar interacciones. De ahí que desde este punto de vista podamos hablar de innovaciones democráticas. A mi juicio, no es otra cosa lo que significa ser realista: ser capaz no solo de mirar sino de ver, de apreciar y gestionar, nuestras capacidades realmente existentes para actuar conjuntamente. Es decir, nuestro poder. 
